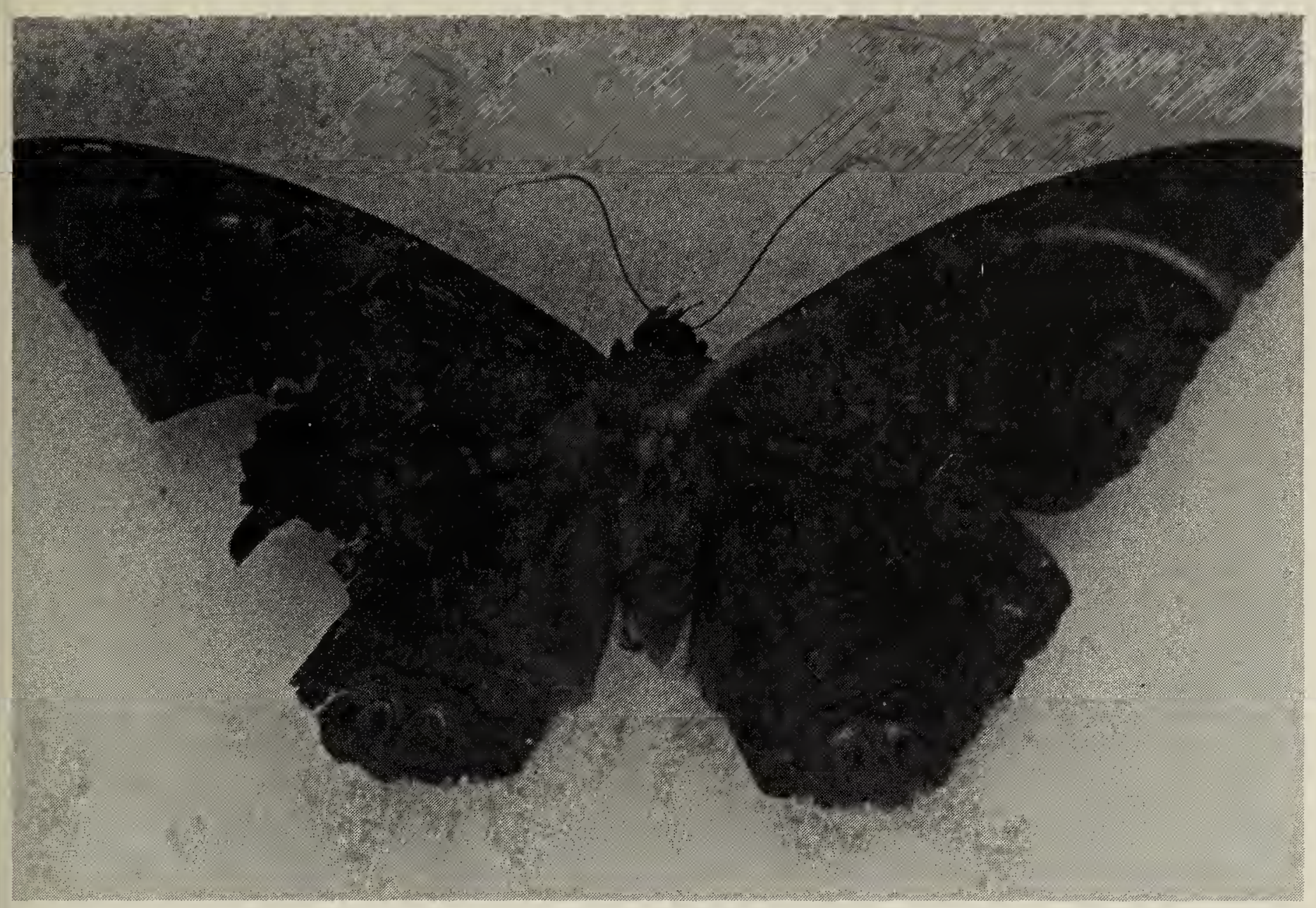

Black Witch Moth

B. J. Godwin

\title{
BLACK WITCH MOTH AT OLDS, ALBERTA
}

B. J. GODWIN, Olds College, Olds, Alberta

According to "The Moth Book" by Holland, the Black Witch, Erebus odora Linnaeus, "occurs abundantly in Southern Florida and the warmer portions of the Gulf States" and is found throughout Central America and tropical South America. "It is found as a straggler into the Northern portions of the United States, and has even been taken in Canada." Although the writer has not checked thoroughly with Alberta collections and museums, some interesting facts are known. The Banff Museum has a worn specimen with the following information: Stan- dish Yard, Banff, Alberta, August 9, 1910 , N. B. Sanson. The University of Alberta Department of Entomology collections have a single worn specimen collected in August 1931 by E. H. Strickland. The Olds College specimen was collected by Steven Bloss and mounted by the writer. It was found fluttering on the window of the family garage, 8 miles north of Olds on August 16, 1974, where it was first mistaken for a bat.

This specimen, with a wing span of $16 \mathrm{~cm}$. (6.3 inches) is an interesting addition to the records of unusual moths collected in Alberta.

LOCAL BIRD NAMES. Brewer's Sparrow: Road-runner (Sask.). From Folk-Names of Canadian Birds, W. L. McAtee. Bull. 149. Nat. Mus. Canada. 1959. 